\title{
Engaging Students in Science through a Nature Hike: A Case of Two Students with ADHD
}

\author{
Ashleigh Moore ${ }^{a}$, Kristy Lynn Daniel* ${ }^{*}$, and Aimée K. Thomas \\ ${ }^{a}$ Department of Psychology, University of Southern Mississippi, Hattiesburg, MS \\ ${ }^{b}$ Department of Biological Sciences, Texas State University, San Marcos, TX \\ 'Department of Biological Sciences, Loyola University New Orleans, New Orleans, LA \\ Student:ashleigh.dais@eagles.usm.edu \\ Mentor:kristydaniel@txstate.edu*
}

\begin{abstract}
Attention-Deficit/Hyperactivity Disorder (ADHD) is becoming prevalent amongst elementary school aged students and can lead to learning disorders. Additionally, informal science education is a field of study that is becoming increasingly popular and important in the world of science, especially with elementary students. Thus, it is important to understand how students with ADHD react to informal learning experiences. We measured learning gains and changes in environmental awareness among 84 fifth grade students that participated in an informal nature hike associated with the Over, Under, and Through: Students' Informal Discover the Environment program. We also used a case study approach to reveal the hike experiences of two students with ADHD. Both students demonstrated increased attention and interest in science during and after their participation in the nature hike. While this is a small scale, case study, findings from this work and related literature suggest that more informal experiential learning opportunities should be integrated into science classes as they help improve student attention, content recall, and attitude toward science.
\end{abstract}

\section{KEYWORDS}

ADHD; Engagement; Environmental Science Education; Informal Science Education; Mobile Technology; Nature Hike

\section{INTRODUCTION}

Attention Deficit Hyperactivity Disorder (ADHD) is of growing concern within elementary schools, with a worldwide prevalence of 5.29\%-7.1\% among children and adolescents. ${ }^{1,2}$ The high numbers of ADHD among students in public schools can interfere with learning and limit interest in science. ${ }^{3,4}$ It is common that students diagnosed with ADHD have difficulties with reading comprehension, ${ }^{5}$ achieving high academic performance, ${ }^{6}$ and developing interpersonal relationships. ${ }^{7}$ Much is known about how students with ADHD interact with peers and learn while in formal traditional classroom settings. ${ }^{7}, 8$ Students with ADHD have a need for special accommodations in learning environments. ${ }^{9}$ For example, accommodations for young students with ADHD include seating students in areas where their behavior can be easily monitored, seating students near positive model students, limiting environmental distractions, creating routine daily schedules, allowing students to be active in a productive manner, assisting with organization through scaffolds, limiting blocks of instructional time, limiting written assignments, and encouraging students to go outside. ${ }^{10}$ Likewise, hands-on, realistic example and the use of physical materials have increased performance and learning. ${ }^{11}$ However, only seven studies have been conducted that explores how elementary school students with ADHD perform (e.g., learning gains, engagement, and content recall) in informal environmental education settings. ${ }^{12-18}$

Informal learning environments typically use experiential learning, ${ }^{19}$ discovery learning, ${ }^{20}$ self-directed learning, ${ }^{21}$ and play-based inquiry ${ }^{22}$ to direct learning experiences. Learning about environmental science naturally lends itself to learning in outdoor environments (e.g., nature preserves, zoos, environmental centers). However, most students do not spend enough time studying, exploring and engaging in the natural history of an environment. ${ }^{23}$ In our current climate, children would prefer to sit inside playing video games or watching TV rather than venture outside and explore nature. ${ }^{24,25}$ Lawrence ${ }^{26}$ looked at behavioral inhibition and executive functioning in boys (ages 6-12) with ADHD in real life settings (playing video games and going to the zoo) and found that they all had poor results for behavioral inhibition and motor control. Educators know that by the time students reach middle school years, their time spent outdoors experiencing nature has diminished and they experience "nature deficit disorder," which may lead to a wide range of behavioral problems. ${ }^{12,23,27}$

Museums, learning centers, and other informal activities (e.g., nature hikes) help build student interest in science. ${ }^{28,}{ }^{29}$ Students that have participated in such informal programs have been found to have high science content learning gains ${ }^{30}$ and positive attitudes with regard to learning science. ${ }^{31}$ Additionally, one month after participation, students still held positive attitudes and were able to easily recall the hands-on interactions. ${ }^{29}$ 
Technology is becoming a standard in educational settings, particularly hand-held devices such as the popular Apple iPads ${ }^{\circledR} .{ }^{32}$ The use of iPads to promote engagement and interactivity during learning has become a popular focus in educational settings. ${ }^{33}$ However, very few studies have looked specifically at the impacts of iPad apps on managing ADHD, ${ }^{34}$ and most have taken place with students at the collegiate level. ${ }^{32,35}$ One investigation ${ }^{35}$ captured evidence that iPad games can be used to improve comprehension and hold user attention among young students with ADHD.

We have situated our study within the informal environmental program-Over, Under, and Through: Students' Informally Discover the Environment (OUTSIDE) — a program that encourages underrepresented 5th grade students to interact with nature and develop observational skills while using a project iPad app. ${ }^{36} \mathrm{~A}$ major goal of this program was to promote equity of access and create opportunities for underrepresented children, including those with ADHD, to access environmental science. In traditional classrooms, it can be problematic for students with ADHD to develop observational skills ${ }^{2}$ and find opportunities to participate in environmental education.

The purpose of our study is to understand how students with ADHD react to science learning in nature through the OUTSIDE program. Our specific research questions include: 1 . What learning gains do students demonstrate after participating in OUTSIDE? 2. How do students with ADHD interact with nature, naturalists, and other students during OUTSIDE?

\section{METHODS AND PROCEDURES}

\section{Participants}

We used a mixed methods approach to complete our study. For our first research question, we gathered data from 84 students to measure learning gains and changes in environmental awareness after participating in the OUTSIDE program. OUTSIDE consists of a series of three hikes that take place once per semester over three semesters (5th through 6th grade). We used all of the student participants in order to obtain large enough numbers to capture potentially significant changes in student learning. This analysis also provides us with data necessary to compare our cases to the general population of students included in the OUTSIDE hikes. For our second research question, we identified two male, fifth-grade students with a documented ADHD diagnosis from our sample population, Taylor (Case Study Participant 1) and Allen (Case Study Participant 2), who participated in the first semester hike. Each of these students used for our case study were males from low-income families, Taylor was black and Allen was Hispanic. To maintain the confidentiality of our participants, we have used pseudonyms for all participants and conducted all research in accordance with the University of Southern Mississippi's Institutional Review Board guidelines (Approval \#CH12072603). All participants were enrolled in one of two southern elementary schools that are part of a high needs district with $84 \%$ poverty and 95\% underrepresented in STEM. When the students arrived at the environmental center for the hike, we placed them into groups of six and assigned a naturalist leader. Taylor and Allen were placed in the same group with Anne serving as their group naturalist. Each boy partnered with a different student within the group and was provided with an iPad with the program app. ${ }^{37}$ During this hike, students participated in activities that focused on practicing skills necessary for becoming a naturalist: making observations, following directions, careful listening, proper nature handling, etc. and learning about human impacts on nature and the nature of science in accordance with the Next Generation Science Standards ${ }^{38}$ (i.e., Disciplinary Core Idea, ESS3.C: Human Impacts on Earth Systems and Cross Cutting Concept: Science Addresses Questions About the Natural and Material World).

\section{Data Collection}

We collected data from a pre/post multiple choice content exam, Likert-style environmental awareness questionnaire, field notes of observations from student actions and communications during the hike, video recordings of student activities from two stations, and student responses during individual, semi-structured follow-up interviews. ${ }^{39}$

Pre/Post/Delayed-Post Content Exam. Students completed a nine-question, multiple-choice content exam before the hike (pre), and immediately following the first hike (post). These questions covered content such as: Which venomous snakes have been identified in Mississippi? Should people touch a snake's head? What is the best way to find the bird in the wild? How do you identify poison ivy? and What should you do is you accidentally touch poison ivy? During the following semesters, students completed a 12-item and another 9-item exam, covering fauna and flora content respectively, before and immediately after each hike. The students were exposed to related content during the OUTSIDE Program through information available on the iPad app and interactions with naturalists. Each assessment was developed and validated by the OUTSIDE research team to measure targeted content learning gains that were expected after participating in each of the OUTSIDE nature hikes: Walk the Train, Meet the Wildlife, and Explore the Plants. 
Pre/Post Environmental Awareness Questionnaire. Students responded to 28 Likert-style questions regarding five facets of awareness (learning about environmental science, interest in nature, technology use, communication skills, and learning science). ${ }^{37}$ Students completed this reliable questionnaire $(\alpha=0.793)$ before the hike (pre), immediately following the hike (post).

Field Notes and Video Recordings. During the entirety of the 10-station nature hike, we gathered data about Taylor's and Allen's actions and remarks. We gathered detailed field notes describing Taylor's and Allen's experiences during the nature hike, including documentation of what each student saw, the students' actions, and students' communications for the entirety of the hike. Each of the targeted students wore a lapel microphone attached to an audio recorder during the hike to allow us to double check the field notes for accuracy. Additionally, we video recorded the entire group interactions at two of the ten stations during the nature hike. The first recording was at a station at the beginning of the hike and the second recording was at a station near the end of the hike. These stations were chosen due to similarities in content related to dams. The naturalist was trained to draw parallels between the two stations and also emphasize differences between the dams. These video recordings allowed us to check for consistency among field notes and compare reliability between observers.

Follow-up Interviews. Upon completion of the hike, we transcribed the field notes and conducted a follow-up interview with each student to better understand their experiences. We asked students to describe their experience, willingness to return to the environmental center or participate in a similar nature hike experience, and any previous experiences or encounters with nature. Some questions included: 1) Tell me about your experiences when you went on the nature hike at Lake Thoreau Environmental Center. 2) What did you learn while you were on this hike? and 3) What did you like best/worst about this trip? We were particularly interested in using these interviews to gather data regarding three types of interactions: 1) Interactions with nature, 2) Interactions with each other and with the naturalist, and 3) Interactions with technology.

\section{Analysis}

To address the first research question, we scored student responses on the content exam and environmental awareness questionnaire. We used a paired dependent t-test to compare averages in content learning gains among all students who participated in the hike to identify if there were significant differences in student learning gains and/or awareness scores pre/post participation. Next, we use a Non-parametric Wilcoxon Signed Rank Test to compare Pre/Post EAQ scores across semesters. To address the second research question, we used data from field notes and student interviews to create individual profiles of each 'Taylor's and Allen's experiences during the hike. We used an inductive approach to code student's actions and communications in search of emergent themes. We used the video recordings of the two stations along the hike to triangulate the findings and ensure the credibility of the created profiles. We report findings from the perspective of a non-participant observer describing student experiences through rich description.

\section{RESULTS}

Learning Gains

We found that while there was an increasing pattern of content learning gains among all student participants during the first and third semester (first semester-Pre: $M=5.26, S D=1.67$; Post: $M=5.68, S D=1.36$; third semester-Pre: $M=3.1, S D=1.67$; Post: $\mathrm{M}=4.63, \mathrm{SD}=1.97$ ), and zero net difference during the second semester (second semester- Pre: $\mathrm{M}=4.92, \mathrm{SD}=1.86$; Post: $\mathrm{M}=4.92$, $\mathrm{SD}=1.81)$ (See Figure 1). However, the gains identified were only significant during the third semester of the program $(t(30)=$ $-3.72, \mathrm{p}=0.001)$. We also found that environmental awareness scores of all our participants steadily increased after participation in OUTSIDE, but there was no statistical difference among these scores $(z(69)=-0.325, p>0.745)$. Of our two case study participants, both students answered one additional question correctly after participating in the OUTSIDE program after the first semester, this was consistent with scores from the other participants. We could not compare later learning gains across semesters as the two case study participants changed schools and dropped out of the OUTSIDE program after the first semester. 


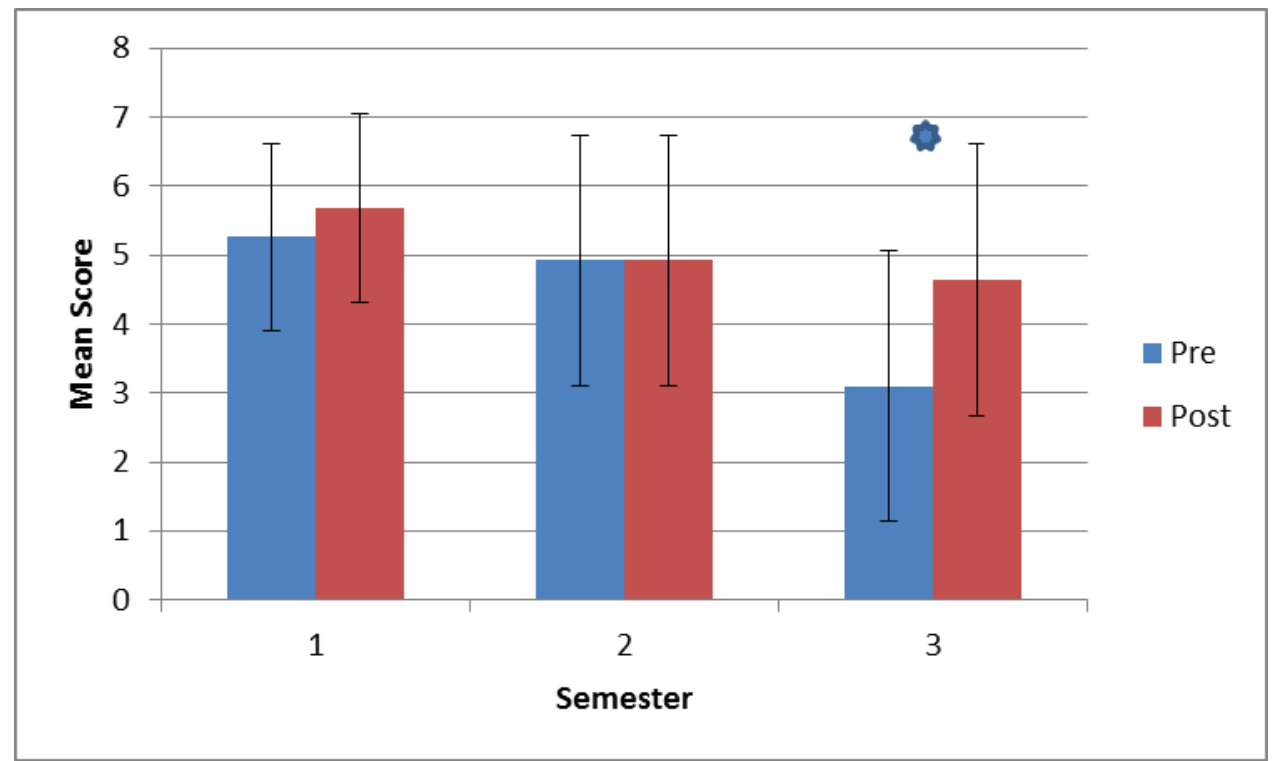

Figure 1. Changes in all participants' pre/post mean scores of content knowledge by semester. There was a significant increase in content knowledge $(t(30)=-3.72, \mathrm{p}=0.001)$ during semester three.

\section{Case Study Findings}

On their first hike, students were eager to participate because of the chance to play with iPads, but initially hesitant to touch things in the natural environment (e.g., plants, insects) for fear of getting dirty. Some initially argued with each other over who got to carry the iPad, but eventually, all became more comfortable interacting with their natural surroundings and less focused on the iPads.

The following are two case study snapshots of Taylor's and Allen's student experience on the first hike. Each of these two students was previously diagnosed with ADHD. These profiles document the experiences of each student while participating in a nature hike and their reflections a month after the experience. The findings are reported from the perspective of a non-participant observer and interviewer, and seek to describe the experience that each student had during each nature hike through rich description.

Taylor. Taylor stated that he enjoyed going outside but, "It's just that I have to go to the park or somewhere because it's crowded over where I live." Thus, Taylor's prior experiences revolved around playing in the city park with cousins where playground equipment was available.

When Taylor first began the OUTSIDE hike, he was observed to be reserved and had little communication with other students. However, once the hike began and the naturalist, Anne, began encouraging the students to interact with nature, Taylor was observed showing interest in the activities at each station and paid attention to questions that were asked. He was polite about answering questions and raised his hand before providing a response and was careful not to interrupt other students when they were speaking. When asked questions, he would nod or shake his head in reply. Taylor stayed at the front of the group and observed organisms highlighted by the naturalist, but he was still hesitant to fully interact with nature. For example, at the first station, Taylor observed the water closely and asked questions about bladderworts when Anne held the plant up. He took photos and recorded notes on the iPad about bladderworts. He withdrew and asked not to have to touch the bladderwort when Anne offered. Instead, Taylor preferred to participate by reading the station introductions and browse the photo gallery in the program app. When his partner had the iPad, he would help spell words and encourage them to take notes about each station.

As the hike proceeded, Taylor became more verbal and offered comments about beavers. They make sounds with their tails as, "a predator alert," build dams, "to stop the water," and use lodges as, "a place where [beavers] hide." Taylor also observed pine trees that had been burned in efforts to reestablish the natural Longleaf Pine Savannah habitat and stated, "They burned the bark on that pine tree. Why would they do that?" Such comments were made without prompting and he verbally responded to questions directed at him by this time. Although Taylor preferred not to touch anything, he engaged with nature through other activities. For example, he cupped his hands around his ears to listen for birds and imitated a tree swaying back and forth when discussing how trees use buttressing to stand in aquatic environments. 
After the hike, Taylor recalled his experiences easily and with excitement. He stated that his favorite part of the hike was, "getting outdoors and seeing all the stuff you can't ordinarily see," recalling the photos he took of the bladderwort and taking notes on the iPad. Taylor stated he could, "still enjoy nature without technology;" however, he was thankful for the iPad because he was able to take notes about the experience to help him remember later.

Allen. While there was a park area within his apartment complex, Allen stated, 'I get bullied by big kids, that's why I don't like to go outside that much." His outdoor experiences were limited to playing kickball, soccer, football, going to the park, and jumping ditches.

Allen was observed to be energetic and consistently active in his participation throughout the hike and responsive to questions. He was very eager to touch plants and quick to pick up leaves, pine cones, and other organisms that he found along the trail, even when asked not to. When Anne pointed out bladderworts, Allen was fascinated by the organism and immediately picked some up from the water, asking, "Is it prey, or like a predator?" He proceeded to take notes on the iPad notepad about how the "bladder" of the plant is used to feed while also assisting classmates in spelling and taking notes. Allen also tried to listen for sounds such as wind blowing, fish bubbling, or frogs and birds calling. Allen was frequently observed volunteering to read the station content aloud and would follow along attentively when other students read.

During a moment of downtime, Allen became visibly distracted and was playing in a moist patch of ground with his foot rather than participating with the group. During this time, he gave no verbal or physical responses to questions. Once Anne began a new activity, showing a dragonfly that she caught, Allen refocused his attention. His attention remained focused as long as he was a part of whatever activity was taking place. For example, at a bird watching station, Allen was alert and involved with searching for nests and listening for the sounds of birds calling. As a classmate began to raise his voice, Allen quickly turned and asked him not to yell because it will scare away the birds. When Anne asked students to stop and cup their hands around their ears to try and hear the sounds happening in nature, Allen would stop and listen for animals, running water, or wind blowing the leaves. He practiced doing such observations even when not prompted, to the point that Allen's interest in nature at times appeared to distract him from the conversation happening amongst the group. For example, Allen would walk around and observe trees, leaves, moss, pine cones, tadpoles in the water, etc. However, as soon as Anne or a student in the group asked him a question, he responded with an appropriate answer, reflecting his attentiveness despite his seemingly distracted actions.

After the hike, Allen was visibly distracted due to not having taken his ADHD medication, although he had taken it on the day of the hike. Still, Allen was able to recall what he saw during the hike, "I heard a goose calling, cricket frogs calling for mating, and we used iPads. That was cool. We got to take pictures, I took pictures like paparazzi, work it." He was interested going on another hike because he liked participating in activities while immersed in nature.

Both Allen and Taylor used the mobile technology provided throughout the hike to facilitate participation and to document experiences. Students used the iPads as a way to access and learn information about nature. Each student also interacted with the naturalists, responding to and asking questions.

\section{DISCUSSION AND CONCLUSIONS}

The purpose of our study was to understand how elementary students with ADHD react to science learning in nature through the OUTSIDE program. We wanted to understand what learning gains students demonstrated and how these students with ADHD interacted on the hike. We know that the elementary-age group has a passion for learning that can diminish in older students. ${ }^{40,41}$ Thus, it is imperative that these students are given an opportunity to maintain their enthusiasm for science. One way students have engaged in learning science through the years is through nature education. However, recent studies suggest that children do not spend enough time studying, exploring and engaging in nature although essential to their overall development. ${ }^{\text {e.g }}$, 23 Thus, we hoped that through the opportunities proved with the OUTSIDE programming, our students would demonstrate content gains and constant engagement in hike activities.

Informal experiences afford better opportunities for learning environmental science than traditional classrooms due to the firsthand interactions with nature $22,42,43$ particularly for students with ADHD. ${ }^{44}$ For example, one of the accommodations suggested for students with ADHD is to encourage them to go outside. In our study, learning takes place in an outdoor setting that should be more suited for students with ADHD. Even when a teacher incorporates active learning in the classroom, immersion within the content is not always possible, particularly with nature. Through OUTSIDE, students who tended to struggle with focusing in a traditional classroom demonstrated constant engagement while on a nature hike. Both students we observed actively participated, were able to recall organisms they had seen, and offered positive feedback about the experience over a month after the hike. This response was consistent with engagement by students that did not have an ADHD diagnosis. ${ }^{37}$ Have found such a response is promising for the field given that our case study participants were able to take part in a learning 
environment in a similar manner as other students. Furthermore, we found that our ADHD students learning gains were consistent with those found in other students. We would have liked to have been able to continuously measure learning gains over multiple semesters, but retention issues made this problematic. As such, we would encourage further studies to explore this facet of research. The evidence from our study still supports the notion that educators should include more hands-on, out-of-class, experiential learning opportunities for students.

When compared to conventional settings, an informal learning environment creates greater interest and helps students build a positive attitude towards science. ${ }^{45}$ One way to promote and continue engagement is through the use of technology. When informal learning environments incorporate technological aspects, there is increased engagement and retention of learning. ${ }^{46,47,48}$ The use of tablet technology in OUTSIDE provided ADHD students with a means of capturing ideas about their experiences in real time: photo evidence, written descriptions, and video/audio recordings of their experiences. This finding is pertinent to the field as past work has only looked at the role of iPads apps in managing ADHD ${ }^{34}$ and improving reading comprehension through games. ${ }^{35}$ In traditional classroom settings, students with ADHD tend to fall behind and recall less information when prompted later.e.g., 6 Through our experiential, multimodal approach, we found that students' long-term recall ability was consistent across all 84 student participants.

While we are making progress on understanding how students, particularly those with ADHD, learn about the environment in informal settings, there is still much to be understood. We need to further examine learning gains at a larger scale. Additionally, it would be useful to explore if we can leverage the use of mobile technology within conventional settings to mimic the impacts of outdoor environmental experiences. It is also essential to explore how teachers may be able to apply the techniques of informal experiences in traditional outdoor classrooms.

\section{ACKNOWLEDGEMENTS}

We thank Marks McWhorter, Carrie Jo Boyce, Dr. Mike Davis, David Reider, Dr. Julie Cwikla, Dr. Brian Gearity, our advisory board, other OUTSIDE volunteers and the Daniel Research Lab for all of their support. This material is based upon work supported by the National Science Foundation under Grant No. (\#1224051).

\section{REFERENCES}

1. Wrońska, N., Garcia-Zapirain, B., and Mendez-Zorrilla, A. (2015). An iPad-Based Tool for Improving the Skills of Children with Attention Deficit Disorder, I J Env Rch and Public Health, 12, 6261-6280.

2. American Psychiatric Association (2013) Diagnostic and Statistical Manual of Mental Disorders, 5th ed.: DSM-5. American Psychiatric Association, Washington.

3. Goepel, J. (2009) Constructing the individual education plan: Confusion or collaboration? Brit J Special Educ 24, 126-132. doi: 10.1111/j.1467-9604.2009.01412.x

4. Grumbine, R., and Alden, P. B. (2006) Teaching science to students with learning disabilities, Sci Teach 73, 26-31.

5. Brock, S. E., and Knapp, P. K. (1996) Reading comprehension abilities of children with attention-deficit/hyperactivity disorder, J Attention Disord 1, 173-185. doi: 10.1177/108705479600100305

6. Biederman, J., Monuteaux, M. C., Doyle, A. E., Seidman, L. J., Wilens, T. E., Ferrero, F., Morgan, C. L., and Faraone, S. V. (2004) Impact of executive function deficits and attention-deficit/hyperactivity disorder (ADHD) on academic outcomes in children, J Consult Clin Psych 71, 757-766. doi: 10.1037/0022-006X.72.5.757

7. Mrug, S., Hoza, B., and Gerdes, A.C. (2001) Children with attention-deficit/hyperactivity disorder: Peer relationships and peeroriented interventions, New Dir Child \& Adol Dev 91, 51-78. doi: 10.1002/cd.5

8. Minskoff, E., and Allsopp., D. (2003) Academic Success Strategies for Adolescents with Learning Disabilities and ADHD. Brookes Publishing, Baltimore, MD.

9. Lam, P., Doverspike, D., Zhao, J., Zhe, J., and Menzemer, C. (2008) An evaluation of a STEM program for middle school students on learning disability related IEPs, J STEM Educ 9, 21-29.

10. Reid, R. (1999) Attention deficit hyperactivity disorder: Effective methods for the classroom, Focus on exceptional children 32, 1.

11. Wolery, M. (1997) Instructional methods with students who have significant disabilities, J Spec Educ 31, 61-79. doi: $10.1177 / 002246699703100106$

12. Allen, K., Varner, K., and Sallee, J. (2011) Addressing nature deficit disorder through primitive camping experiences, J Extension 49, n3.

13. Beyer, K. M., Heller, E. F., Bizub, J. M., Kistner, A. J., Szabo, A., Shawgo, E. E., and Zetts, C. J. (2015) More than a pretty place: Assessing the impact of environmental education on children's knowledge and attitudes about outdoor play in nature, $I J$ Env Rch and Public Health 12, 2054-2070.

14. Kuo, F., and Taylor, A. F. (2004) A potential natural treatment for Attention-Deficit/Hyperactivity Disorder: Evidence from a national study, Am J Public Health 94, 1580-1586. 
15. Taylor, A. F., and Kuo, F. E. (2009) Children with attention deficits concentration better after walk in the park, $J$ Attention Disorders 12, 402-409. doi: 10.1177/1087054708323000

16. Taylor, A. F., and Kuo, F. E. M. (2011) Could exposure to everyday green spaces help treat ADHD? Evidence from children's play settings, Applied Psy: Health and Well-Being 3, 281-303.

17. Van den Berg, A. E., and Van den Berg, C. G. (2011) A comparison of children with ADHD in a natural and built setting, Child: Care, Health, and Development 37, 430-439.

18. Wells, N. M. (2014) The role of nature in children's resilience: Cognitive and social processes, in Greening in the Red Zone (95109). Springer, Dordrecht, Netherlands.

19. Kolb, D. A. (1984) Experiential Learning: Experience as the Source of Learning and Development. Prentice Hall, Englewood Cliffs, NJ.

20. Bruner, J. (1960) The Process of Education. Harvard University Press, Cambridge, MA.

21. Deci, E. L., and Ryan, R. M. (1982) Intrinsic motivation to teach: Possibilities and obstacles in our colleges and universities, New Dir Teach Learn 10, 27-35. doi: 10.1002/tl.37219821005

22. Henderson, T., and Atencio, D. (2007) Integration of play, learning, and experience: what museums afford young visitors, Ear Child Educ J 35, 245-251. doi: 10.1007/s10643-007-0208-1

23. Louv, R. (2005) Last Child in the Woods: Saving our Children from the Nature-Deficit Disorder. Algonquin Books, Chapel Hill, NC.

24. Roberts, D., and Foehr, U. (2004) Kids and Media in America. University Press, Cambridge.

25. Weiss, M. D., Baer, S., Allan, B. A., Saran, K., and Schibuk, H. (2011) The screens culture: Impact on ADHD. ADHD Attention Deficit and Hyperactivity Disorders 3, 327-334.

26. Lawrence, V., Houghton, S., Tannock, R., Douglas, G., Durkin, K., and Whiting, K. (2002). ADHD outside the laboratory: Boys' executive function performance on tasks in videogame play and on a visit to the zoo, J Abnormal Child Psy 30, 447-462. doi: 10.1023/A:1019812829706

27. Driessnack, M. (2009) Children and nature-deficit disorder. J Specialists in Pediatric Nursing 14, 73-75.

28. Mayhew, L. M., and Finkelstein, N. D. (2009) Learning to communicate about science in everyday language through informal science education, AIP Conf Proc 1179, 205-208. doi:10.1063/1.3266716

29. Nadelson, L., and Jordan, J. (2012) Student attitudes toward and recall of outside day: An environmental science field trip, J Educ Res 105, 220-231. doi: 10.1080/00220671.2011.576715

30. Bartley, J. E., Mayhew, L. M., and Finkelstein, N. D. (2009) Promoting children's understanding and interest in science through informal education, Phys Educ Res Conf 1179, 93-96.

31. Wulf, R., Mayhew, L. M., and Finkelstein, N. D. (2009) Impact of informal science education on children's attitudes about science, AIP Conf Proc 1179, 93-96. doi: 10.1063/1.3515238

32. Drake, N., Fletcher, L., Tabb, W., Smith, W., Forsythe, C., Sutton, S., and Bryant, K. (2014, January). The iPad as instructional tool: An examination of Jackson State University faculty implementation experience, in NAAAS Conference Proceedings (p. 289). National Association of African American Studies.

33. Omiteru, E. (2012, June) Using iPad apps to enhance teaching and learning, in World Conference on Educational Multimedia, Hypermedia and Telecommunications (Vol. 2012, No. 1, 736-740).

34. Kumaragama, K., and Dasanayake, P. (2015) iOS Applications (apps) for Attention Deficit Hyperactivity Disorder (ADHD/ADD): A preliminary investigation from Australia, J Mobile Tech in Med, 4(2), 33-39.

35. Wasniewski, E. (2013, March) One-on-one with an iPad: A faculty perspective on iPad supports for students with disabilities, in Society for Information Technology \& Teacher Education International Conference (Vol. 2013, No. 1, pp. 4346-4351).

36. Over, Under, and Through: Students' Informally Discover the Environment, bttp:// wmw.usm.edu/get-outside (accessed Aug 2014)

37. Boyce, C. J., Mishra, C., Halverson, K. L., and Thomas, A. K. (2014) Getting students outside: Using technology as a way to stimulate engagement, J Sci Educ Technol 23, 815-826. doi: 10.1007/s10956-014-9514-8

38. Next Generation Science Standards: 5-ESS3 Earth and Human Activity, http:// www.nextgenscience.org/5ess3-earth-buman-activity (accessed Nov 2014)

39. Patton, M.Q. (2002) Qualitative Research \& Evaluation Methods. Sage, Thousand Oaks, CA.

40. McPhail, J.C., Pierson, J.M., Freeman, J.G., Goodman, J., and Ayappa, A. (2000) The role of interest in fostering sixth grade students' identities as competent learners, Curriculum Inq 30, 43-70.

41. Harvard Family Research Project: Findings from HFRP's study of predictors of participation in out-of-school time activities Fact sheet, http:/ / www. hfrp.org/publications-resources/browse-our-publications/findings-from-hfrp-s-study-or-predictors-of-participation-in-out-ofschool-time-activities-fact-sheet (accessed Oct 2014)

42. Speaker, K. M. (2001) Interactive exhibits theory: Hints for implementing learner-centered activities in elementary classrooms, Educ 121, 610-614.

43. Falk, J. H., and Diekring, L. D. (2010) The 95 percent solution: School is not where most Americans learn most of their science, Am Sci 98, 386-493.

44. Ames, C. (2013) My learning curve on learning disabilities, Liberal Educ 99, 56-60. 
45. National Research Council (2009) Learning Science in Informal Environments: People, Places, and Pursuits. The National Academics Press, Washington, D.C.

46. Clough, G., Jones, A.C., McAndrew, P., and Scanlon, E. (2008) Informal learning with PDAs and smartphones, J Comput Assist Lear 24, 359-371. doi: 10.1111/j.1365-2729.2007.00268.x

47. Sung, Y.-T., Chang, K.-E., Lee, Y.-H., and Yu, W.-C. (2008) Effects of a mobile electronic guidebook on visitors' attention and visiting behaviors, Educ Technol Soc 11, 67-80.

48. Woodruff, A., Aoki, P.M., Hurst, A., and Szymanski, M.H. (2001) Electronic guidebooks and visitor attention, Proc Int Conf Cult Heritage Technol.

\section{ABOUT THE STUDENT AUTHOR}

Ashleigh Davis Moore received her B.S. in Psychology, minor in Biological Sciences at the University of Southern Mississippi in 2014 where she completed this research as part of her honors thesis under the direction of Kristy L. Daniel, Ph.D. Through working with programs such as OUTSIDE, her desire to discover how students learn science was strengthened, and she has plans to further her education and implement new strategies and programs for science education in school systems.

\section{PRESS SUMMARY}

Attention disorders can make learning difficult for students and cause frustration. We brought students out of the classroom to learn science on a nature hike. We found evidence that using tablet technology in this outdoor setting increased students' attention and improved interest in learning science. 